\title{
PENERAPAN BOOTSTRAP DALAM METODE MINIMUM COVARIANCE DETERMINANT (MCD) DAN LEAST MEDIAN OF SQUARES (LMS) PADA ANALISIS REGRESI LINIER BERGANDA
}

\author{
Ni Putu Iin Vinny Dayanti ${ }^{\S 1}$, Ni Luh Putu Suciptawati ${ }^{2}$, Made Susilawati ${ }^{3}$ \\ ${ }^{1}$ Jurusan Matematika Fakultas MIPA - Universitas Udayana [Email: vinnyiindayanti@ gmail.com] \\ ${ }^{2}$ Jurusan Matematika Fakultas MIPA - Universitas Udayana [Email: putusuciptawati@yahoo.co.id] \\ ${ }^{3}$ Jurusan Matematika Fakultas MIPA - Universitas Udayana [Email: mdsusilawati@unud.ac.id] \\ ${ }^{\S}$ Corresponding Author
}

\begin{abstract}
Ordinary Least Squares (OLS) Method is a good method to estimate regression parameters when there is no violation in classical assumptions, such as the existence of outlier. Outliers can lead to biased parameters estimator, therefore we need a method that can may not affected by the existence of outlier such as Minimum Covariance Determinant (MCD) and Least Median of Squares (LMS). However, the application of this method is less accurate when it is used for small data. To overcome this problem, it was aplicated bootstrap method in MCD and LMS to determine the comparison of bias in parameters which were produced by both methods in dealing outlier in small data. The used bootstrap method in this study was the residual bootstrap that works by resampling the residuals. By using $95 \%$ and $99 \%$ confidence level and 5\%, 10\% and 15\% outlier percentage, MCD-bootstrap and LMS-bootstrap give value of parameter estimators which were unbias for all percentage of outlier. We also found that the widht of range which produced by MCD-bootstrap method was shorter than LMS-bootstrap method produced. This indicates that MCD-bootstrap method was a better method than LMS-bootstrap method.
\end{abstract}

Keywords: outliers, bias, robust, Minimum Covariance Determinant, Least Median of Squares, bootstrap residual

\section{PENDAHULUAN}

Analisis regresi linier berganda merupakan analisis yang digunakan untuk menyelidiki hubungan linier antara dua atau lebih peubah prediktor terhadap peubah respon yang berskala minimal interval (Neter, et al [1]).

Metode kuadrat terkecil (MKT) merupakan metode penduga parameter regresi yang baik bila tidak terjadi pelanggaran asumsi klasik, seperti adanya pencilan. Pencilan merupakan data yang pengamatannya berada jauh dari sekelompok data amatan lainnya yang menyebabkan penduga parameter bersifat bias (Neter, et al [1]). Metode yang bisa mengatasi pencilan yaitu Minimum Covariance Determinant (MCD) dan Least Median of Squares (LMS). Namun penggunaan metode MCD dan LMS kurang tepat apabila berhadapan dengan data berukuran kecil. Penelitian ini dilakukan dengan menerapkan bootstrap pada kedua metode (MCD-bootstrap) dan (LMSbootstrap) untuk mengetahui perbandingan bias pada parameter yang dihasilkan dalam mengatasi pencilan pada data berukuran kecil.

Metode bootstrap yang digunakan adalah bootstrap residual yang bekerja dengan meresampling sisaannya (residual) (Efron \& Tibshirani [2]).

Metode Minimum Covariance Determinant (MCD) memiliki prinsip kerja menggunakan vektor rataan dan matriks kovarians dengan membentuk subsampel $H$ yang berukuran $h$ dari sampel berukuran $n$ amatan yang matriks kovariansnya memiliki determinan terkecil (Hubert \& Debruyne [3]). Nilai $h$ diperoleh dari:

$$
h=\left\lfloor\frac{n+p+1}{2}\right\rfloor, h \leq n
$$


Selanjutnya dicari vektor rataan $\boldsymbol{V}_{M C D}$ dan matriks kovarians $S_{M C D}$ serta jarak mahalanobis kekar $R D$ dengan menggunakan rumus (Hubert \& Debruyne [3]):

$$
\begin{gathered}
\boldsymbol{V}_{M C D}=\frac{1}{h} \sum_{i \in H} x_{i} \\
S_{M C D}=\frac{1}{h} \sum_{i \in H}\left[x_{i}-\boldsymbol{V}_{M C D}\right]\left[x_{i}-\boldsymbol{V}_{M C D}\right]^{T} \\
R D=\sqrt{\left(x_{i}-\boldsymbol{V}_{M C D}\right)^{T} S_{M C D}^{-1}\left(x_{i}-\boldsymbol{V}_{M C D}\right)}
\end{gathered}
$$

Selanjutnya ditentukan Fast MCD (Rousseeuw [4]) yaitu terlebih dahulu dengan menentukan subsampel $H_{1}$ yang berukuran $h$ kemudian dapat dihitung nilai $\boldsymbol{V}_{M C D}$ dan $S_{M C D}$ dengan misalkan sebagai $\boldsymbol{V}_{\mathbf{1}}$ dan $S_{1}$ serta menghitung determinan dari $S_{1}$ atau $\operatorname{det}\left(S_{1}\right)$. Jika $\operatorname{det}\left(S_{1}\right) \neq 0$ maka dilanjutkan dengan menghitung nilai $R D$ yang diurutkan dari terkecil hingga terbesar. Pada iterasi berikutnya yaitu $\mathrm{H}_{2}$ akan diambil sebanyak $h$ pengamatan dengan jarak $R D$ terkecil. Demikian seterusnya hingga mencapai konvergen $\operatorname{det}\left(S_{i+1}\right)=\operatorname{det}\left(S_{1}\right)$. Kemudian pilih himpunan $H$ yang memiliki determinan $S_{M C D}$ terkecil serta menghitung nilai $\boldsymbol{V}_{M C D}$ dan $S_{M C D}$. Maka selanjutnya data dapat diboboti dengan

$$
W_{i}=\left\{\begin{array}{lr}
1, j i k a\left(x_{i}-\boldsymbol{V}_{M C D}\right)^{T} S_{M C D}^{-1}\left(x_{i}-\boldsymbol{V}_{M C D}\right) \leq \chi_{p ; 1-\alpha}^{2} \\
0, & \text { lainnya }
\end{array}\right.
$$

Sehingga dapat dibentuk matriks

$$
W_{M C D}=\left[\begin{array}{cccc}
w_{11} & w_{12} & \cdots & w_{1 n} \\
w_{21} & w_{22} & \cdots & w_{2 n} \\
\vdots & \vdots & \vdots & \vdots \\
w_{n 1} & w_{n 2} & \cdots & w_{n n}
\end{array}\right]
$$

Dan diperoleh penduga MCD

$$
\hat{\beta}_{M C D}=\left(X^{T} W_{M C D} X\right)^{-1}\left(X^{T} W_{M C D} Y\right)
$$

Least Median of Squares (LMS) merupakan metode yang bekerja dengan meminimalkan median (nilai tengah) dari kuadrat residual $\left(e_{i}^{2}\right)$ (Rousseeuw [5] yaitu:

$$
M_{J}=\min \left\{\text { median } e_{i}^{2}\right\}
$$

dilakukan pada urutan nilai residual kuadrat.

Langkah awal metode LMS adalah menentukan kuadrat nilai error dari MKT sehingga diperoleh nilai $M_{1}$. Selanjutnya dihitung nilai $h_{1}$ dengan rumus:

$$
h_{i}=\left\lceil\frac{n+p+1}{2}\right\rceil
$$

Kemudian pada iterasi ke-2 $\left(M_{2}\right)$ diambil pengamatan sejumlah $h_{1}$ dari $M_{1}$ dengan jarak nilai $\left(e_{i}^{2}\right)$ yang minimum. Demikian seterusnya sampai iterasi berakhir pada iterasi ke- $i$ yaitu saat $h_{i}=h_{i+1}$ Selanjutnya dapat dihitung bobot $w_{i i}$ dengan rumus:

$$
w_{i i}=\left\{\begin{array}{lc}
1, & j i k a\left|e_{i} / \hat{\sigma}\right| \leq \alpha \\
0, & \text { lainnya }
\end{array}\right.
$$

dengan

$$
\hat{\sigma}=1,4826\left[1+\frac{5}{n-p}\right] \sqrt{M_{J}}
$$

maka dapat dibentuk matriks $W$ :

$$
W=\left[\begin{array}{cccc}
w_{11} & w_{12} & \cdots & w_{1 n} \\
w_{21} & w_{22} & \cdots & w_{2 n} \\
\vdots & \vdots & \vdots & \vdots \\
w_{n 1} & w_{n 2} & \cdots & w_{n n}
\end{array}\right]
$$

dengan entri matriks $w_{i j}=0$, dengan $i \neq j$. Penduga parameter regresi LMS dapat dihitung dengan menggunakan rumus:

$$
\hat{\beta}_{L M S}=\left(X^{T} W X\right)^{-1}\left(X^{T} W Y\right)
$$

Langkah-langkah bootstrap residual (Efron \&Tibshirani [2]) adalah menentukan nilai $\hat{Y}$ yang dihasilkan oleh model analisis regresi, selanjutnya dapat diperoleh nilai residual yaitu, $e=Y-\hat{Y}$. Selanjutnya mengambil sampel bootstrap berukuran $n$ dari $e_{1}, e_{2}, e_{3}, \ldots e_{n}$ secara acak dengan pengembalian, sehingga diperoleh sampel bootstrap pertama $e^{*}=$ $\left(e_{1}^{*}, e_{2}^{*}, \ldots e_{n}^{*}\right)$. Kemudian hitung nilai bootstrap untuk $Y^{*}$ dengan cara:

$$
X \hat{\beta}+e^{*}=Y^{*}
$$

Lebih lanjut lagi dihitung koefisien regresi untuk sampel bootstrap $Y^{*}$ sehingga diperoleh $\hat{\beta}^{*}$. Iterasi terus dilakukan sampai pada batas replikasi yang diinginkan.

\section{METODE PENELITIAN}

Penelitian ini menggunakan data simulasi melalui pembangkitan data berdistribusi normal dengan bantuan software R i386 3.1.3. Data ini terdiri dari sisaan dan dua peubah prediktor yang akan digunakan untuk menentukan peubah responnya. Persentase pencilan yang diberikan 
sebesar 5\%, 10\% dan 15\%. Serta dengan menggunakan alpha $(\alpha)$ sebesar 0,05 .

Langkah pembangkitkan data yaitu dengan membangkitkan nilai sisaan (e) berdistribusi $N(0,1)$. Kemudian membangkitkan peubah $X_{1} \sim N(50,3)$ dan $X_{2} \sim N(80,5)$ sebanyak 40 amatan, dengan memisalkan $\beta_{0}=2$, dan $\beta_{1}=\beta_{2}=1$, akan diperoleh nilai $Y$ dengan membentuk persamaan

$$
Y=\beta_{0}+\beta_{1} X_{1}+\beta_{2} X_{2}+\varepsilon .
$$

Pencilan yang dibangkitkan pada data sisaan dengan $\mu=5$ dan $\sigma=0,1$ pada tiap persentase pencilan. Selanjutnya menghitung nilai $Y$ yang sudah terkontaminasi pencilan. Kemudian dilakukan uji kenormalan, pendeteksian multikolinearitas, pemeriksaan pencilan dan dilanjutkan menganalisis dengan MKT.

Langkah berikutnya menganalisis dengan metode MCD-Bootstrap yaitu menduga nilai $\beta_{0}, \beta_{1}$ dan $\beta_{2}$ dari matriks kovarian robust yang telah diperoleh dari penduga MCD. Resampling sisaan dengan bootstrap residual sebanyak 500 dan 1.000 kali dilakukan dengan menggunakan selang kepercayaan 95\% dan 99\%. Selanjutnya menganalisis dengan metode LMS-Bootstrap. Resampling sisaan yang diperoleh dari metode LMS dengan bootstrap residual sebanyak 500 dan 1.000 kali dan dilakukan dengan menggunakan selang kepercayaan $95 \%$ dan 99\%. Kemudian membandingkan hasil yang diperoleh dengan MCD-bootstrap dan LMSbootstrap.

\section{HASIL DAN PEMBAHASAN}

\section{A. Hasil Pengujian Asumsi Kenormalan Data Dengan Uji Anderson-Darling}

Berdasarkan hasil pengujian asumsi kenormalan dapat dilihat pada tabel 1 berikut:

Tabel 1. Uji Kenormalan Data

\begin{tabular}{|c|c|c|}
\hline $\begin{array}{c}\text { Persentase } \\
\text { pencilan }\end{array}$ & $p$-value & Keterangan \\
\hline $\begin{array}{c}\text { Data awal (tanpa } \\
\text { pencilan) }\end{array}$ & 0,780 & Normal \\
\hline $5 \%$ & 0,03635 & Tidak normal \\
\hline $10 \%$ & $<0,005$ & Tidak normal \\
\hline $15 \%$ & $<0,005$ & Tidak normal \\
\hline
\end{tabular}

Hasil uji kenormalan pada Tabel 1, data dengan pencilan sebesar 5\%, 10\% serta $15 \%$ memiliki nilai $p$-value $<\alpha$, hal ini menunjukkan data dengan pencilan memiliki sebaran data yang tidak normal.

\section{B. Pendeteksian Multikolinearitas}

Untuk melihat masalah multikolinearitas maka dilakukan dengan melihat nilai korelasi yang dihasilkan antara peubah prediktor.

Tabel 2. Korelasi Antarvariabel

\begin{tabular}{|c|c|c|}
\hline Variabe1 & $Y$ & $X_{1}$ \\
\hline$X_{1}$ & 0,309 & \\
\hline$X_{2}$ & 0,052 & \\
\hline & 0,873 & $-0,161$ \\
\hline
\end{tabular}

Dari Tabel 2 dapat dilihat bahwa nilai korelasi yang dihasilkan pada $X_{1}$ dan $X_{2}$ sebesar -0,161 yang menunjukkan peubah $X_{1}$ dan $X_{2}$ memiliki hubungan yang berlawanan arah namun tidak terjadi masalah multikolinearitas.

\section{Pemeriksaan Pencilan atau Outlier}

Pemeriksaan pencilan dilakukan dengan menggunakan Robust Distance (RD) lalu membandingkannya dengan nilai chi-square. Dalam pemeriksaan menggunakan RD diperoleh hasil seperti pada Tabel 3:

Tabel 3. Pemeriksaan Pencilan dengan Robust Distance (RD)

\begin{tabular}{|c|c|c|c|c|}
\hline \multirow{2}{*}{ Data } & Persentase & \multicolumn{2}{|c|}{ Data pengamatan ke- } & Banyak \\
\cline { 3 - 5 } & pencilan & outlier orthogonal & bad leverage & pencilan \\
\hline \multirow{4}{*}{40} & $5 \%$ & $1,2,3,4,5,6$ & 31 & 7 \\
\cline { 2 - 5 } & $10 \%$ & $1,2,4,7,18,23,25$ & 3,31 & 9 \\
\cline { 2 - 5 } & $15 \%$ & $3,7,18,23$ & $1,2,31$ & 7 \\
\hline
\end{tabular}

Tabel 3 menunjukkan hasil pemeriksaan pencilan yaitu dengan persentase pencilan 5\% terdeteksi 7 pengamatan sebagai pencilan dan 9 pengamatan yang merupakan pencilan pada persentase $10 \%$ dan pada peresentase $15 \%$ terdeteksi 7 pengamatan sebagai pencilan. Pencilan yang terdeteksi merupakan jenis outlier orthogonal maupun bad leverage.

\section{Analisis Data dengan Metode Kuadrat Terkecil (MKT)}

Analisis data dengan MKT akan menggunakan selang kepercayaan $95 \%$ dan $99 \%$. 
Tabel 4. Penduga Parameter dengan MKT

\begin{tabular}{|c|c|c|c|c|c|c|}
\hline \multirow{2}{*}{$\begin{array}{c}\text { Jumlah } \\
\text { Pencilan }\end{array}$} & Parameter & Estimasi & $\begin{array}{c}\text { Selang } \\
\text { Kepercayaan }\end{array}$ & Ket & $\begin{array}{c}\text { Selang } \\
\text { Kepercayaan }\end{array}$ & Ket \\
\hline $\begin{array}{c}\text { Data tanpa } \\
\text { pencilan }\end{array}$ & $\beta_{1}$ & 0.9752 & $0.8514-1.0991$ & Tidak bias & $0.8092-1.1412$ & Tidak bias \\
\cline { 3 - 8 } & $\beta_{2}$ & 1.0608 & $0.9952-1.1265$ & Tidak bias & $0.9729-1.1488$ & Tidak bias \\
\hline \multirow{2}{*}{$5 \%$} & $\beta_{1}$ & 1.3865 & $0.9669-1.1462$ & Bias & $0.9059-1.3255$ & Bias \\
\cline { 2 - 8 } & $\beta_{2}$ & 1.0591 & $0.9641-1.1541$ & Tidak bias & $0.9317-1.1864$ & Tidak bias \\
\hline \multirow{2}{*}{$10 \%$} & $\beta_{1}$ & 1.4079 & $0.9021-1.1182$ & Bias & $0.8286-1.3344$ & Bias \\
\cline { 2 - 7 } & $\beta_{2}$ & 1.1412 & $0.8732-0.9877$ & Bias & $0.8343-1.0229$ & Bias \\
\hline \multirow{2}{*}{$15 \%$} & $\beta_{1}$ & 1.4283 & $0.8549-1.0999$ & Bias & $0.7715-1.3449$ & Bias \\
\cline { 2 - 7 } & $\beta_{2}$ & 1.1854 & $0.8816-1.0114$ & Bias & $0.8375-1.1413$ & Bias \\
\hline
\end{tabular}

Karena nilai penduga penduga parameter $\beta_{1}$ dan $\beta_{2}$ yang dihasilkan oleh MKT bersifat tidak bias hanya saat pencilan $5 \%$ untuk $\beta_{2}$, hal ini berarti MKT mengalami bias saat adanya pencilan. Maka akan dilanjutkan dengan menganalisis dengan metode Minimum Covariance Determinant (MCD)-Bootstrap dan Least Median of Squares (LMS)-Bootstrap.

\section{E. Analisis Data dengan Metode Minimum Covariance Determinant (MCD)-Bootstrap}

Berdasarkan hasil analisis dengan metode MCD-bootstrap dengan resampling 500 dan 1000 kali dapat dilihat pada Tabel 5 dan 6 adalah berikut:

Tabel 5. Pendugaan parameter dengan metode MCD-bootstrap dengan $\mathrm{B}=500$ kali resampling

\begin{tabular}{|c|c|c|c|c|c|c|c|}
\hline \multirow[b]{2}{*}{$\begin{array}{l}\text { Jumlah } \\
\text { Pencilan }\end{array}$} & \multirow[b]{2}{*}{ Parameter } & \multirow[b]{2}{*}{ Estimasi } & \multicolumn{2}{|c|}{ Selang Kepercayaan 950 } & \multirow{2}{*}{ Estimasi } & \multicolumn{2}{|c|}{ Selang Kepercayaan 99\% } \\
\hline & & & $\begin{array}{c}\text { Selang } \\
\text { Kepercayaan }\end{array}$ & Ket & & \begin{tabular}{|c|} 
Selang \\
Kepercayaan
\end{tabular} & Ket \\
\hline $5 \%$ & $\beta_{1}$ & 1.0929 & $0.9871-1.1938$ & Tidak bias & 1.0908 & $0.9592-1.221$ & Tidak bias \\
\hline & $\beta_{2}$ & 0.9676 & 0.9031- & & 0.9693 & 0.8841 & Tidak b \\
\hline $10 \%$ & $\beta_{1}$ & 1.1929 & $1.0706-1.3156$ & Tidak bias & 1.1958 & $1.0243-1.362$ & Tidak bias \\
\hline & $\beta_{2}$ & 0.9065 & 0.8275-0.9874 & Tidak bias & 0.905 & p.7970-1.017 & Tidak bias \\
\hline $15 \%$ & $\beta_{1}$ & 1.1406 & 1.0014 & Tidak b & 1.1366 & 0.9587 & Tidak bias \\
\hline & $\beta_{2}$ & 0.9436 & & & 09466 & $0.8325-1.062$ & Tidak bias \\
\hline
\end{tabular}

Tabel 6. Pendugaan parameter dengan metode MCD-bootstrap dengan B=1000 kali resampling

\begin{tabular}{|c|c|c|c|c|c|c|c|}
\hline \multirow{2}{*}{$\begin{array}{c}\text { Jumlah } \\
\text { Pencilan }\end{array}$} & Parameter & Estimasi & & \multicolumn{2}{|c|}{ Selang Kepercayaan 95\% } & & \multicolumn{2}{|c|}{ Selang Kepercayaan 99\% } \\
& & & Kepercayaan & Ket & Estimasi & $\begin{array}{c}\text { Selang } \\
\text { Kepercayaan }\end{array}$ & Ket \\
\hline $5 \%$ & $\beta_{1}$ & 1.0897 & $0.9879-1.1930$ & Tidak bias & 1.091 & $0.9582-1.2227$ & Tidak bias \\
\hline & $\beta_{2}$ & 0.9698 & $0.9031-1.0369$ & Tidak bias & 0.9689 & $0.8840-1.0559$ & Tidak bias \\
\hline $10 \%$ & $\beta_{1}$ & 1.1919 & $1.0723-1.3139$ & Tidak bias & 1.1937 & $1.0392-1.3471$ & Tidak bias \\
\hline & $\beta_{2}$ & 0.9074 & $0.8287-0.9862$ & Tidak bias & 0.9063 & $0.8070-1.0079$ & Tidak bias \\
\hline $15 \%$ & $\beta_{1}$ & 1.1354 & $1.0050-1.2686$ & Tidak bias & 1.1396 & $0.9574-1.3162$ & Tidak bias \\
\hline & $\beta_{2}$ & 0.9471 & $0.8618-1.0330$ & Tidak bias & 0.9443 & $0.8307-1.0541$ & Tidak bias \\
\hline
\end{tabular}

Dari Tabel 5 dan 6 diperoleh bahwa penduga parameter yang dihasilkan oleh metode
MCD-bootstrap bersifat tidak bias dengan resampling 500 maupun 1000 kali. Hal ini berarti bahwa penduga parameter $\beta_{1}$ dan $\beta_{2}$ yang dihasilkan oleh metode bootstrap residual berada di dalam selang kepercayaan 95\% dan $99 \%$.

\section{F. Analisis Data dengan Metode Least Median of Squares (LMS)-Bootstrap}

Berdasarkan hasil analisis dengan metode LMS-bootstrap dengan resampling 500 dan 1000 kali dapat dilihat pada Tabel 7 dan 8 adalah berikut:

Tabel 7. Pendugaan parameter dengan metode Least Median of Squares (LMS)Bootstrap dengan 500 kali resampling

\begin{tabular}{|c|c|c|c|c|c|c|c|}
\hline \multirow{2}{*}{$\begin{array}{l}\text { Jumlah } \\
\text { Pencilan }\end{array}$} & \multirow[b]{2}{*}{ Parameter } & \multirow[b]{2}{*}{ Estimasi } & \multicolumn{2}{|c|}{ Selang Kepercayaan 95\% } & \multirow{2}{*}{ Estimasi } & \multicolumn{2}{|c|}{ Selang Kepercayaan $99 \%$} \\
\hline & & & $\begin{array}{c}\text { Selang } \\
\text { Kepercayaan }\end{array}$ & Ket & & $\begin{array}{c}\text { Selang } \\
\text { Kepercayaan }\end{array}$ & Ket \\
\hline $5 \%$ & $\beta_{1}$ & 0.9122 & $0.8474-1.0577$ & Tidak bias & 0.9079 & $0.8078-1.0973$ & Tidak bias \\
\hline & $\beta_{2}$ & 1.0854 & $1.0397-1.1764$ & Tidak bias & 1.088 & 1.0142-1.2019 & Tidak bias \\
\hline $10 \%$ & $\beta_{1}$ & 0.908 & $0.8355-1.0868$ & Tidak bias & 0.9086 & $0.7926-1.1297$ & Tidak bias \\
\hline & $\beta_{2}$ & 1.0924 & $1.0350-1.1979$ & Tidak bias & 1.0915 & $1.0072-1.2257$ & Tidak bias \\
\hline $15 \%$ & $\beta_{1}$ & 0.9264 & $0.6754-0.9689$ & Tidak bias & 0.9334 & $0.6353-1.0090$ & Tidak bias \\
\hline & $\beta_{2}$ & 1.0827 & $0.9379-1.1294$ & Tidak bias & 1.0781 & $0.9127-1.1546$ & Tidak bias \\
\hline
\end{tabular}

Tabel 8. Pendugaan parameter dengan metode Least Median of Squares (LMS)Bootstrap dengan 1000 kali resampling

\begin{tabular}{|c|c|c|c|c|c|c|c|}
\hline \multirow{2}{*}{$\begin{array}{l}\text { Jumlah } \\
\text { Pencilan }\end{array}$} & \multirow[b]{2}{*}{ Paramete } & \multirow[b]{2}{*}{ Estimasi } & \multicolumn{2}{|c|}{ Selang Kepercayaan 95\% } & \multirow{2}{*}{ Estimas } & \multicolumn{2}{|c|}{ Selang Kepercayaan $99 \%$} \\
\hline & & & $\begin{array}{c}\text { Selang } \\
\text { Kepercayaan }\end{array}$ & Ket & & $\begin{array}{c}\text { Selang } \\
\text { Kepercayaan }\end{array}$ & Ket \\
\hline $5 \%$ & $\beta_{1}$ & 0.9102 & $0.8456-1.0595$ & Tidak bias & 0.9062 & $0.8174-1.0877$ & Tidak bi \\
\hline & $\beta_{2}$ & 1.0866 & $1.0386-1.1775$ & Tidak bias & 1.0891 & $1.0201-1.1960$ & Tidak b \\
\hline $10 \%$ & $\beta_{1}$ & 0.9073 & $0.8282-1.0941$ & Tidak bias & 0.9132 & $0.7947-1.1276$ & Tidak bias \\
\hline & $\beta_{2}$ & 1.0927 & $1.0302-1.2027$ & Tidak bias & 1.0889 & 1.0086-1.2243 & Tidak bias \\
\hline $15 \%$ & $\beta_{1}$ & 0.9314 & $0.6832-0.9611$ & Tidak bias & 0.9316 & 0.6341-1.0102 & Tidak bias \\
\hline & $\beta_{2}$ & 1.0796 & $0.9436-1.1237$ & Tidak bias & 1.0792 & $0.9122-1.1551$ & Tidak bia \\
\hline
\end{tabular}

Dari Tabel 7 dan 8 diperoleh bahwa dengan menganalisis menggunakan metode LMSbootstrap, selang kepercayaan 95\% dan 99\% dapat mencakup nilai parameternya. Hal ini berarti hasil yang diperoleh dengan metode LMS-bootstrap, nilai penduga parameter $\beta_{1}$ dan $\beta_{2}$ bersifat tidak bias. 


\section{G. Perbandingan hasil MCD-Bootstrap dan LMS-Bootstrap}

Perbandingan hasil analisis dengan metode MCD-bootstrap dan LMS-bootstrap dapat dilihat pada Tabel 9 dan 10 adalah berikut:

Tabel 9. Lebar selang pada selang kepercayaan 95\% untuk $\beta_{1}$ dan $\beta_{2}$ pada metode MCD-bootstrap dan LMS-bootstrap

\begin{tabular}{|c|c|c|c|c|c|}
\hline \multirow{3}{*}{ Parameter } & \multirow{3}{*}{$\begin{array}{c}\text { Persentase } \\
\text { Pencilan }\end{array}$} & \multicolumn{4}{|c|}{ Metode } \\
\hline & & \multicolumn{2}{|c|}{ MCD-bootstrap } & \multicolumn{2}{|c|}{ LMS-bootstrap } \\
\hline & & $B=500$ & $B=1000$ & $B=500$ & $B=1000$ \\
\hline \multirow[t]{3}{*}{$\beta_{1}$} & $5 \%$ & 0.2067 & 0.205 & 0.2102 & 0.2138 \\
\hline & $10 \%$ & 0.2449 & 0.2415 & 0.2512 & 0.2658 \\
\hline & $15 \%$ & 0.2707 & 0.2635 & 0.2935 & 0.2778 \\
\hline \multirow[t]{3}{*}{$\beta_{2}$} & $5 \%$ & 0.1337 & 0.1338 & 0.1367 & 0.1389 \\
\hline & $10 \%$ & 0.1598 & 0.1574 & 0.1629 & 0.1725 \\
\hline & $15 \%$ & 0.1762 & 0.1712 & 0.1914 & 0.18 \\
\hline
\end{tabular}

Tabel 10. Lebar selang pada selang kepercayaan 99\% untuk $\beta_{1}$ dan $\beta_{2}$ pada metode MCD-bootstrap dan LMS-bootstrap

\begin{tabular}{|c|c|c|c|c|c|}
\hline \multirow{2}{*}{ Parameter } & \multirow{2}{*}{\begin{tabular}{c} 
Persentase \\
\cline { 3 - 6 }
\end{tabular}} & \multicolumn{4}{|c|}{ Metode } \\
\cline { 3 - 6 } & & \multicolumn{2}{|c|}{ MCD-bootstrap } & \multicolumn{2}{c|}{ LMS-bootstrap } \\
\cline { 3 - 6 }$\beta_{1}$ & $5 \%$ & 0.2625 & 0.2644 & 0.2895 & 0.2703 \\
\cline { 2 - 6 } & $10 \%$ & 0.3376 & 0.3078 & 0.3371 & 0.3329 \\
\cline { 2 - 6 } & $15 \%$ & 0.3562 & 0.3588 & 0.3737 & 0.3761 \\
\hline \multirow{2}{*}{$\beta_{2}$} & $5 \%$ & 0.1716 & 0.1718 & 0.1877 & 0.1759 \\
\cline { 2 - 6 } & $10 \%$ & 0.2208 & 0.2008 & 0.2185 & 0.2157 \\
\cline { 2 - 6 } & $15 \%$ & 0.2297 & 0.2333 & 0.2419 & 0.2428 \\
\hline
\end{tabular}

Dari Tabel 9 dan 10 menunjukkan bahwa dengan selang kepercayaan 95\% dan 99\%, metode MCD-bootstrap menghasilkan nilai lebar selang yang lebih kecil dibandingkan metode LMS-bootstrap untuk semua persentase pencilan pada $\beta_{1}$ dan $\beta_{2}$.

\section{KESIMPULAN}

Metode MCD-bootstrap maupun LMSbootstrap merupakan metode yang baik dalam menduga nilai parameter saat data mengandung pencilan. Pada selang kepercayaan 95\% dan 99\%, metode MCD-bootstrap dan LMSbootstrap menghasilkan nilai penduga parameter yang bersifat tidak bias untuk seluruh persentase pencilan. Karena lebar selang kepercayaan yang dihasilkan metode MCD-bootstrap lebih pendek dibanding metode LMS-bootstrap, maka dapat dikatakan metode MCD-bootstrap lebih akurat.

\section{DAFTAR PUSTAKA}

[1] Neter, J., Wasserman, W., \& Kutner, M. 1997. Model Linier Terapan Buku II: Analisis Regresi Linier Sederhana. (Terjemahan Bambang Sumantri). Bandung: Jurusan FMIPA-IPB.

[2] Efron, B., \& Tibshirani, R.J. 1993. An Introduction to the Bootstrap. New York London: Chapman \& Hall.

[3] Hubert, M., \& Debruyne, M. 2009. Minimum Covariance Determinant. WIREs Computational Statistics 2010, pp 36-43.

[4] Rousseeuw, P.J. 1999. Fast Algorithm for the Minimum Covariance Determinant Estimator. Technometrics, august 1999. Vol. 41, No. 3 American Statistical Association and the American Society for Quality, pp.212-223.

1984. Least Median of Squares Regression. Journal of the American Statistical Association, pp. 871880. 